\title{
Avian corticosteroid-binding globulin: biological function and regulatory mechanisms in physiological stress responses
}

\author{
Hai-Yan Lin ${ }^{1 \dagger}$, Gang Song ${ }^{1 \dagger}$, Fumin Lei ${ }^{1^{*}}$, Dongming $\mathrm{Li}^{2^{*}}$ and Yanhua Qu ${ }^{1^{*}}$
}

\begin{abstract}
Corticosteroid-binding globulin (CBG) is a high-affinity plasma protein that binds glucocorticoids (GCs) and regulates their biological activities. The structural and functional properties of CBG are crucial to understanding the biological actions of GCs in mediating stress responses and the underlying mechanisms. In response to stress, avian CBGs modulate the free and bound fractions of plasma corticosterone (CORT, the main GC), enabling them to mediate the physiological and behavioral responses that are fundamental for balancing the trade-off of energetic investment in reproduction, immunity, growth, metabolism and survival, including adaptations to extreme high-elevation or highlatitude environments. Unlike other vertebrates, avian CBGs substitute for sex hormone-binding globulin (SHBG) in transporting androgens and regulating their bioavailability, since birds lack an Shbg gene. The three-dimensional structures of avian and mammalian CBGs are highly conserved, but the steroid-binding site topographies and their modes of binding steroids differ. Given that CBG serves as the primary transporter of both GCs and reproductive hormones in birds, we aim to review the biological properties of avian CBGs in the context of steroid hormone transportation, stress responses and adaptation to harsh environments, and to provide insight into evolutionary adaptations in CBG functions occurred to accommodate physiological and endocrine changes in birds compared with mammals.
\end{abstract}

Keywords: Corticosteroid-binding globulin, Stress response, Glucocorticoids, Sex hormone-binding globulin

\section{Corticosteroid-binding globulin (CBG) is a major determinant of glucocorticoid (GC) actions during stress}

The stress response in vertebrates, including activation of the hypothalamic-pituitary-adrenal (HPA) axis and sympathetic adrenomedullary (SA) system, enables them

\footnotetext{
* Correspondence: leifm@ioz.ac.cn; lidongming@hebtu.edu.cn;

${ }^{\dagger}$ Hai-Yan Lin and Gang Song contributed equally to this work. Zoology, Chinese Academy of Sciences, Beijing 100101, China

${ }^{2}$ Key Laboratory of Animal Physiology, Biochemistry and Molecular Biology of Hebei Province, College of Life Sciences, Hebei Normal University,

(c) The Author(s). 2021 Open Access This article is licensed under a Creative Commons Attribution 4.0 International License, which permits use, sharing, adaptation, distribution and reproduction in any medium or format, as long as you give appropriate credit to the original author(s) and the source, provide a link to the Creative Commons licence, and indicate if changes were made. The images or other third party material in this article are included in the article's Creative Commons licence, unless indicated otherwise in a credit line to the material. If material is not included in the article's Creative Commons licence and your intended use is not permitted by statutory regulation or exceeds the permitted use, you will need to obtain permission directly from the copyright holder. To view a copy of this licence, visit http://creativecommons.org/licenses/by/4.0/ The Creative Commons Public Domain Dedication waiver (http://creativecommons.org/publicdomain/zero/1.0/) applies to the data made available in this article, unless otherwise stated in a credit line to the data. challenges, facilitating physiological and behavioral adaptations. The HPA axis is governed by the secretion of the corticotropin-releasing hormone $(\mathrm{CRH})$ from the hypothalamus, which triggers the release of the adrenocorticotropic hormone $(\mathrm{ACTH})$ from the anterior pituitary into the circulation. In turn, ACTH exerts its actions on the adrenal cortex and initiates the rapid release of glucocorticoids (GCs) into the blood. As the principal active forms of GCs, cortisol and corticosterone (CORT) are fundamental for orchestrating a series of behavioral and physiological activities in response to environmental challenges and restoring the homeostatic balance [1]. 
During acute stressful situations, rapid elevations in plasma GCs exert a plethora of central and systemic activities that are vital for promoting survival, such as acute enhancement of metabolic processes, inflammatory reaction, and energy mobilization. Subsequently, the negative feedback of GCs on the hypothalamus and pituitary effectively inhibits the adrenal secretion of GCs, allowing a return to behavioral and physiological homeostasis. On the other hand, chronic activation of the HPA axis and long-term elevated concentrations of GCs cause deleterious effects on reproduction, immunity, development, metabolic activities, behavior, etc., resulting in serious or even life-threatening sequelae [2].

The HPA axis is involved in many physiological functions making an organism's response to environmental changes appropriate for its reproductive status. There exists a reciprocal relationship between the HPA and the hypothalamic-pituitary-gonadal (HPG) axes. Activation of the HPA axis and GC secretion, especially in response to extreme stressors, has an inhibitory effect on gonadal hormone secretion through central actions in the hypothalamus and pituitary, causing potential cessation of reproduction and facilitating survival under extreme circumstances [3, 4]. Alternatively, sex hormones such as testosterone and estrogen can modulate the response of the HPA axis by influencing the response and secretion of releasing factors and GCs [3, 5], thereby blunting stress responses to preserve reproduction.

In the systematic circulation, biologically active steroids are transported by steroid-binding proteins, including corticosteroid-binding globulin (CBG, also known as transcortin) and sex hormone-binding globulin (SHBG), with the former transporting GCs and progesterone, and the latter carrying androgens and estrogens. Mendel's Free Hormone Hypothesis states that free hormone in the plasma is biologically active [6]; on the other hand, the protein-bound hormone concentration also affects intracellular hormone concentrations and its biologic activity [7]. Plasma CBG and SHBG bind steroids with high affinity and specificity, and play important roles in controlling steroid access to target tissues $[8,9]$.

The steroid-binding properties of CBG in the plasma have been determined in mammals and most nonmammalian terrestrial vertebrates, including amphibians, reptiles and birds [10]. In humans and rats, CBG binds as much as $90 \%$ of circulating cortisol or CORT $[10,11]$. In addition to GCs, CBG also transports progesterone with a comparably high affinity $[10,12,13]$. The CBG protein shares little sequence homology with other steroid carriers, and belongs to the serine proteinase inhibitor A (SERPINA) superfamily, but lacks proteinase inhibitory properties [14]. Crystal structure investigations of rat or human CBG have revealed that it folds into a stressed SERPIN conformation when it binds GCs and progesterone, with the reactive center loop (RCL) fully exposed from the central $\beta$-sheet $A$; whereas it adopts a relaxed conformation when RCL undergoes proteolysis and inserts within the protein core, causing the irreversible release of its bound steroids [15-17]. In this allosteric mechanism that modulates steroid binding and release, helix D plays a key role via coupling RCL movement and the integrity of the steroid-binding site [18]. Therefore, the function of CBG in terms of its specific ligand binding and targeted steroid release links with the positioning of the RCL prior to and after protease cleavage [18]. Importantly, proteolytic cleavage of CBG results in a marked but not a complete loss of steroid binding activity, characterized by a ten-fold lower affinity. Thus circulatory GCs are buffered by two pools, intact CBG with a high affinity and to a far lesser extent by proteolytically cleaved CBG with a low affinity [19]. The latter pool, as a backup buffer to that of the intact CBG, is of physiological significance, particularly in inflammation and sepsis, representing a mechanism for the delivery and probably a direct release of the hormone to inflammatory loci [11]. Furthermore, plasma CBG is a glycoprotein, with $30 \%$ of its mass represented by N-linked oligosaccharide chain [14]. Mammalian CBGs have five to six $\mathrm{N}$-glycosylation sites, one of which resides in RCLs in human and rat CBGs [20]. Glycosylation of CBGs influences steroid-binding activity, and disruption of a highly conserved $\mathrm{N}$-glycosylation site causes a loss of steroid binding [20,21].

It is therefore evident that CBG has functions beyond a simple plasma steroid transporter, and plays a major role in bioavailability, local delivery, and cellular signal transduction of GCs [22, 23]. This is evidenced in a mouse model genetically deficient for CBG, which exhibits fatigue, poor response to septic shock, and an inability to appropriately respond to excessive free CORT [22]. It has also been reported that CBG-deficient mice have markedly reduced total circulating CORT at rest, insufficient GC signaling, decreased endocrine (free CORT concentration) and behavioral responses after prolonged stress, as well as intolerance to life-threatening inflammation [24]. Interestingly, free CORT levels are normal under resting conditions in CBG-deficient mice [24], leading to the debate that the primary function of CBG seems to be the retention of a circulating pool readily available in an emergency situation [25]. In fact, the critical role of CBG as a cortisol reservoir, in particular for stress-induced CORT delivery to the brain, has been underlined by the following studies. CBG-deficient mice are insensitive to stress, have a blunted CORT response, no free CORT rise in the hippocampus and increased CORT clearance, stemming from a smaller CORT reservoir in blood $[26,27])$. Remarkably, CBG is intrinsically expressed in various brain regions and in neurons and glial cells of humans and mice [28]. Thus, 
given that CORT unbound to CBG are cleared from the blood more quickly, the maintenance of a plasma pool of GCs by CBG should always be considered.

Patients with CBG deficiencies caused by nonsynonymous single nucleotide polymorphisms (SNPs) and amino acid substitutions often present with low plasma cortisol levels, are overweight, and suffer from chronic pain and/or fatigue. For example, homozygous or heterozygous carriers of CBG Lyon (D367N) and/or W12stop (W12 null mutation) have chronic asthenia, fatigue, hypotension, low morning total plasma cortisol levels, abnormal regulation of HPA axis and reduced cortisol peak levels upon ACTH stimulation [29, 30]. Mutations causing CBG deficiencies include transcortin Leuven (L93H) [31-34], Lyon (D367N) [29, 30, 35-37] and E102G [38] that have reduced steroid-binding affinity or capacity; G237V [39] and W371S [35] characterized by no detectable cortisol-binding activity; W12stop [30, 36] and L5stop [40] that are not produced due to null mutations; A51V $[38,41]$ that has reduced protein production and secretion. Most of these CBG deficiencies are considered rare, except for CBG A51V, which occurs at a relatively high frequency of approximately 1:36 in over 2000 Han Chinese [38]. Furthermore, the CBG rs7161521 SNP is also reported to be associated with diurnal and stress-induced salivary cortisol and HPA axis activity in children [42]. Thus, these mutations that influence CBG production or its cortisol-binding activity raised the functional importance of CBG. Free cortisol levels in individuals carrying D367N are within normal ranges [29], suggesting a net result or a homeostatic balance of reduced total cortisol level and appropriate response of the hypothalamic/pituitary adrenal axis.

Overall, mammalian CBGs have been characterized at the molecular level. SerpinA6 genes, which encode CBG, originated as a result of SerpinA gene duplications in early terrestrial vertebrate genomes [43]. Unlike mammalian CBGs, bird CBGs bind progesterone and androgen with high affinities and determine their biological activities [13, 44]. Moreover, accumulating evidence has documented the function of avian CBGs in endocrine and neural responses to stressors. The main goal of this review is to address the conserved/specialized functions of avian CBGs and to provide some insight into how they evolved to control steroid transport and bioavailability in response to environmental and physiological stressors.

\section{Coping with changing environments and adaptive stress responses in wild birds}

When an unpredictable circumstance such as predation or adverse weather conditions occurs, a short-term stress response so called the "fight-or-flight" response is triggered within seconds to minutes in vertebrates. In birds, CORT is the primary GC involved in the modulation of stress response. In wild-caught birds subjected to a standardized capture-handling-restraint stress protocol, CORT levels usually increase within several minutes of initial capture and handling, then sustain until 30 to $60 \mathrm{~min}$, and decline afterwards $[45,46]$. Such an acute stress response is generally beneficial for immediate survival. However, if the stressor continues, CORT levels remain elevated and the bird enters long-term chronic stress response [47].

As volant vertebrates, birds have the widespread distribution range covering diverse environments globally, and display extraordinary diversities and plasticity in phenotypic traits and behavior, allowing them to adapt to the most extreme environments on the Earth, from the polar region to the Himalayan alpine. Under extreme conditions, birds have evolved various coping strategies of stress physiology, among which the dependence on extreme habitats is related to the balance between stress response patterns and reproductive requirements [48]. For instance, the Snow Petrel, Pagodroma nivea, is a long-lived bird with very low fecundity and often breeds in ice fields on or near the Antarctic continent. Young birds show increased CORT levels in response to acute stress and a tendency of nest abandonment, but this breeding disruption is also compromised in older individuals [48]. Indeed, it has been widely recognized that the GC response of arctic birds to unpredictable perturbation factors, such as inclement weather, patchy food and predators, is suppressed while breeding, allowing continued nesting and successful reproduction [49-52].

Over the last two centuries, urbanization, characterized by human population aggregation and urban expansion, has driven unprecedented environmental and ecological changes. Consequently, wild birds have had to face emerging stressors caused by profound changes in their habitats and food resources. A number of bird species that have adapted to urbanization are manifested by their strong dispersal abilities and a high level of risktaking [53]. In a large-scale study of the juvenile House Sparrow (Passer domesticus) in urban and rural sites, feather CORT levels are positively correlated with the extent of urbanization and stress-induced plasma CORT levels, suggesting the impact of urban environmental conditions on stress physiology and sensitivity [54]. However, other studies show inconsistent profiles of stress physiology in different populations. The European Blackbird (Turdus merula) in urban areas have lower plasma CORT levels than their conspecifics living in forests [55]. The human commensal population of the House Sparrow shows lower stress-induced free CORT levels than its non-commensal population living in ancestral habitats [56]. In the urban populations of the Song Sparrow (Melospiza melodia) and the adult House Sparrow along the urbanization gradient, no detrimental effects of urbanization on stress physiology are observed $[57,58]$. Notably, in the extreme environment of the Tibetan Plateau, there are no significant differences in 
acute adrenocortical responses in the Eurasian Tree Sparrow (Passer montanus) relative to the lowland populations, further suggesting a mask effect by human activities, food resources and shelter [46, 50]. Overall, different urban birds have different coping styles and urbanization-adapted stress physiology. The reduced stress response could be an adaptive strategy for species that adjust to and thrive in the urban environment, avoiding deleterious effects caused by chronic stress.

\section{The function of CBGs in avian stress responses}

While modulating CORT synthesis/sensitivity of the HPA axis to feedback is one mechanism, altering CBG activity is another way for modulating the stress sensitivity to respond to environmental perturbations. In birds, CBG has been proved to function as a dynamic component and an essential mediator of the stress physiology in response to unpredictable perturbations. As aforementioned, free CORT is the biologically active fraction, while the CBG-bound fraction is a biologically relevant reservoir. Thus, the measurement of free GC concentrations in stress response has constraints and is not fully reliable [59]. In this respect, plasma levels of total CORT, free CORT and the binding affinity/capacity of CBG are all fundamental measurements in evaluative and comparative field studies to assess stress physiology of different bird species [59, 60]. For example, in the House Sparrow, CBG levels change correspondingly with total CORT levels, resulting in static free CORT concentrations year-round, whereas in the White-crowned Sparrow (Zonotrichia leucophrys), levels of CBG and free CORT change simultaneously when total CORT levels remain stable [61]. It is becoming clear that in response to stressors, changes in circulating GC levels and CBG capacity act in species-, life-history stage- and habitat environment-specific manners.

\section{Avian CBGs in species-specific stress responses}

In response to the acute stress, the CBG binding capacity can also change when the total CORT increased significantly, which would result in remarkable variations in the circulating free CORT levels. Although the majority of bird species can remain CBG capacity invariable in response to acute handling stress, several species exhibit a decrease in the CBG binding capacities (reviewed by [62]). For example, several species such as the Common Tern (Sterna hirundo), the Red Crossbill (Loxia curvirostra), the Zebra Finch (Taeniopygia guttata), the American Kestrel (Falco sparverius) and the Laysan Albatross (Phoebastria immutabilis), CBG steroid-binding capacity significantly declines within 30-60 min of capture stress, serving to increase free CORT levels in response to acute stressors [62, 63]. Some other species remain static CBG capacities in response to the acute stress of capture-handling-restraint
[63], e.g., the House Sparrow [63], the European Starlings (Sturnus vulgaris) [63], the Japanese Quail (Coturnix japonica) [63], the White-crowned Sparrow [63], the Blacklegged Kittiwakes (Rissa tridactyla) [64], the Albert's Towhee (Pipilo aberti) [65], the Canyon Towhee (Pipilo fuscus) [65], the Curve-billed Thrasher (Toxostoma curvirostre) [65] and the Northern Mockingbird (Mimus polyglottos) [65]. Interestingly, the CBG binding capacities of Eurasian tree sparrows can even increase in response to acute stress in the second nestling stage, although it remains stable in other life-history stages [66]. Furthermore, the CBG binding capacity also varies with nutrient status. In the Whitecrowned Sparrow, food deprivation at 1,2 , and $6 \mathrm{~h}$ significantly increases free CORT levels above baseline, whereas circulating levels of CBG are significantly reduced at 22-h fasting when free CORT reaches normal levels [67]. Such discrepancy of $\mathrm{CBG}$ changes in response to acute stress and nutrient status may be explained by some underlying protective mechanisms, such as the increase of bioavailable (free) CORT for minimizing extraordinary levels of CORT secretion, the regulation of negative feedback, the increase of glucose utilization, or upregulation of CORTdependent metabolic functions (Reviewed by [59]). It is interesting that plasma CBG levels respond very dynamically in response to stress in some species but not in others, which suggests either rapid proteolysis of CBG or a marked increase in its plasma clearance. Considering that the causes and consequences of the variations in CBG binding capacity are rather complex that is involved in a suite of energy-dependent biochemical and molecular pathways $[68,69]$, further studies are needed to test the biological, ecological significance of CBG binding variations during the acute stress response or energydependent stress.

Apart from the binding capacity, the CBG binding affinity of birds also varies significantly with species (Reviewed by [62]), e.g., from $1.48 \mathrm{nM}$ (Zebra Finch, Taeniopygia guttata) [63] to 25.4 nM (Pied Flycatcher, Ficedula hypoleuca) [70]). The observed species-specific CBG binding affinity could derive from the CBG protein topological structures. How the key amino acid sites evolve to increase the CBG binding affinity is critically essential for better understanding the interspecies differences of CBG binding affinity. Unfortunately, limited information is available for explaining this question to date. Further studies integrating the fields of biological function, phylogeny, and evolution are needed to uncover these unsolved questions.

\section{Life-history stage dependent variations of avian CBGs and stress responses}

Birds have evolved a variety of life-history strategies in response to seasonality [71, 72]. Theoretically, animals with fewer reproductive opportunities are expected to invest 
more value over current reproduction. Birds with fewer breeding chances (short-lived within a lifetime or limited opportunities to re-nest within a season) should reduce stress reactivity to minimize the risk of nest abandonment $[64,73]$, then CORT and CBG levels change accordingly. In most avian species, seasonal fluctuations of baseline and stress-induced CBG capacity and CORT release reflect their life-history stage dependent strategies for adapting to environmental variations through optimizing their physiological and behavioral states. For example, in the House Sparrow, capture-handling-restraint stress responses during the pre-basic molt are lower than those during the breeding; in addition, the seasonal regulation of CORT response appears to be correlated with the HPA axis sensitivity that also varies seasonally $[56,74]$. In the Eurasian Tree Sparrow, seasonal fluctuations of stress responses also show sex-specific patterns. Male birds have higher baseline CBG capacities during the nest-building, the first egg-laying, and the first nestling stages, and increased stress-induced CBG capacities during the second nestling stage [66]. Females have higher baseline plasma CBG levels during the nest-building stage, increased stress-induced CBG during the second egg-laying and the second nestling stages, but decreased stress-induced CBG during the nest-building stage [66]. Moreover, CORT response and CBG levels also vary with breeding sub-stages, i.e., maximal free CORT levels are lower during the nestbuilding stage than those during the early nestling stages, and females exhibit lower maximal CORT during the early nestling compared to later stages, suggesting the intensity of the adrenocortical response to acute restraint stress is negatively correlated with reproductive investment during breeding [75]. In a high-productivity breeding colony of the Tufted Puffins (Fratercula cirrhata), levels of CBG, total baseline CORT, free baseline CORT, and total maximum CORT are all higher during the pre-egg-laying stage than for the late incubation and late chick-rearing stages. Moreover, total baseline levels of CORT during the chickrearing stage are 2-4 times higher at the low productivity colony, suggesting the higher cost of reproduction performance [76]. Overall, it is important to incorporate CBG and free CORT analysis into studies of the stress response, which would be better for explaining the relationship of stress reactivity to life-history strategies [62]. We may receive bias conclusions if solely relying on a value whereas in fact, CBG levels and free CORT may differ. Therefore, ignoring the effect of binding globulins may lead to a misinterpretation of the stress responses in birds [62].

\section{CBG and CORT levels coping with extreme environmental conditions - high latitudes}

As mentioned above, avian species breeding in harsh environments, including high latitudes and elevations, have reduced adrenocortical responses to long-term environmental stress, enabling them to maximize reproductive success as a physiological trade-off $[49,51,52]$. The Arctic birds during breeding season, such as the Lapland Longspur (Calcarius lapponicus), the Common Redpoll (Carduelis flammea), the Snow Bunting (Plectrophenax nivalis) at Barrow and Toolik Lake, the Pied Flycatcher (Ficedula hypoleuca) and the Willow Warbler (Phylloscopus trochilus) breeding in Swedish Lapland (Ammarnäs), diminish the sensitivity of the adrenocortical response to acute stress as well as behavioral and physiological responses to CORT treatment, allowing birds to adapt to territorial behavior and to breed successfully in the face of the capricious environment [51, 77, 78]. In a comparative study of populations of the White-crowned Sparrow breeding at different latitudes, baseline and stress-induced CORT levels are similar; however, CBG binding capacity is significantly higher in subspecies gamblii breeding at high latitude than in pugetensis or oriantha breeding at middle or low latitude [79]. As a result, gambelii, with the shortest breeding seasons and the lowest free CORT levels among the three subspecies, is the least sensitive to environmental perturbations [79]. Arctic birds also suppress their adrenocortical response to acute capture-handling-restraint stress, especially in birds providing most parental care [80]. Besides, the suppression level varies with the intensity of the parental care. In the Rock Ptarmigan (Lagopus mutus), the Pectoral Sandpiper (Calidris melanotos) and the Red Phalarope (Phalaropus fulicaria), either females or males that provide most parental care, show lower stress-induced CORT levels and GC responses during the breeding season $[80,81]$.

\section{CBG and CORT levels coping with extreme environmental conditions - high elevations}

In another highly extreme environment, the Tibetan Plateau, two endemic species, the White-rumped Snowfinch (Onychostruthus taczanowskii) and the Rufousnecked Snowfinch (Pyrgilauda ruficollis), show no significant variation in adrenocortical response to stress between the early breeding and the pre-basic molt stages, which differs from those observed in arctic birds [49]. However, the extent of lowered adrenocortical responses can vary seasonally. The White-rumped and Rufousnecked Snowfinches have remarkably suppressed acute stress-induced CORT levels during the wintering stage relative to other stages, such as the early breeding, late breeding and pre-basic molting [82]. Moreover, the Twites (Carduelis flavirostris) on the Tibetan Plateau have lowered adrenocortical responses during pre-basic molt than those during the early breeding [78]. Overall, blunt adrenocortical responses, as physiological and ecological strategies, allow avian species to cope with extremes and to obtain maximal reproductive success through modulating the trade-off of energetic investment between reproduction and immediate survival. We predict that the higher binding capacity of CBG in 
extreme circumstances would contribute to reducing stress-induced free CORT levels for buffering the acute stress sensitivity.

\section{Zebra finch CBG crystal structure illustrates evolutionary conserved and distinct properties of avian CBGs}

Primary sequences of avian CBGs share limited identity with mammalian CBGs [83] (Fig. 1). Chicken (Gallus gallus) and Zebra Finch CBGs have been experimentally isolated and identified by mass spectrometry and molecular cloning, which provides evidence that chicken ENSGALG00000010969 and Zebra Finch ENSTGUG00000012647 (or LOC100228673) genes encoding CBG are incorrectly annotated as SerpinA4 and alpha-1-antiproteinase 2, respectively [83]. To the best of our knowledge, CBG in other avian species, as yet, has not been correctly annotated as CBG or SerpinA6. Notably, orthologs of CBG have been identified in several reptiles, whose CBG sequences are more similar to birds than mammals, especially within their steroid-binding sites, and their Nglycosylation and RCL sequences [83], indicating that SerpinA6 is an evolutionarily conserved gene.

The crystal structure of Zebra Finch CBG in complex with cortisol has been solved to $2.4 \AA$ resolution [83]. The three-dimensional structures of Zebra Finch [83], rat $[18]$ and human $[85,86]$ CBGs binding with cortisol resemble each other and exhibit evolutionarily conserved properties. However, their steroid-binding sites differ in several important aspects. Firstly, in mammalian CBGs, a conserved tryptophan residue (W362 in rat and W371 in human) in the steroid-binding pocket, which is critical for steroid-ligand binding, distinguishes it from other members of the SERPINA family; however, in Zebra Finch CBG, this tryptophan is replaced by an asparagine (N385), and this asparagine residue is present in this position in other avian CBG sequences. Secondly, among the 10-12 specific residues of rat CBG that directly participate in steroid binding, only 5 are conserved in Zebra Finch or other avian CBGs, and these differences account for the distinct high-affinity steroid-binding properties of avian CBGs for progesterone and androgens as well as GCs. Thirdly, mammalian CBGs have five or six $\mathrm{N}$-glycosylation sites, some of which are strictly conserved and essential for steroid-binding activity $[14,20$, 87]. By contrast, Zebra Finch CBG has only three Nglycosylation sites, one of which, N385, has been proved to participate in proper protein folding and high affinity steroid-binding site formation [83].

The GCs in both Zebra Finch CBG and rat CBG crystal structures are at the interface of helix $\mathrm{A}$, helix $\mathrm{H}$ and $\beta$-sheet B (Fig. 2). There are also important differences in the positioning of cortisol in the Zebra Finch CBG and rat CBG steroid-binding sites. Firstly, in rat CBG, the cortisol A ring forms a hydrophobic bond with A13 and V17, while in Zebra Finch CBG, it is held by V32 and A36. Secondly, in rat CBG, W362 forms a hydrogen bond and strong stacking interactions with the surface of cortisol, whereas in Zebra Finch CBG, N385 forms a hydrogen bond with the hydroxyl group of cortisol at C17 [83]. Overall, the Zebra Finch CBG structure reveals not only an evolutionarily conserved property but also the distinct steroid-binding activities of bird CBGs when compared with mammalian CBGs.

\section{Key characteristics of avian CBGs distinct from mammals: specific transporters of androgens}

High affinity binding of dihydrotestosterone (DHT), testosterone and estradiol to SHBG have been observed in the blood of amphibians, reptiles and mammals [10]. Remarkably, in birds, plasma SHBG has never been identified $[10,13,44]$ and gene encoding SHBG appears to be absent. Thus a specific transporter for androgens and estrogens in birds has remained elusive. In the Dark-eyed Junco (Junco hyemalis), CBG binds to CORT and progesterone with essentially similar high affinity, i.e., with the equilibrium dissociation constant for $\left[{ }^{3} \mathrm{H}\right]$ CORT of $<5 \mathrm{nM}$, whereas it binds androgens with approximately five-fold lower affinity [44]. However, this is still within the nanomolar range, and more than $90 \%$ of circulating testosterone is assumed to be bound with $\mathrm{CBG}$ in this species [44]. Comparable binding properties of CBG with CORT, progesterone and testosterone are also observed in 23 avian species belonging to 8 orders and 12 families [13]. A detailed study shows that Zebra Finch CBG has greater affinities for cortisol and progesterone (IC50 value of $\sim 2 \mathrm{nM})$ than for CORT $(\sim 4 \mathrm{nM})$, and moderate affinities for testosterone $(\sim 18 \mathrm{nM})$ and DHT $(\sim 11 \mathrm{nM})$ [83]. Therefore, avian CBG is considered to substitute SHBG in transporting androgens and regulating their bioavailability [44].

In the crystal structure of Zebra Finch CBG, R246 forms a hydrogen bond with the hydroxyl group of cortisol at C21 and the carbonyl group at C20. Remarkably, substitution of R246 with glutamine significantly decreases the binding affinity for progesterone but does not affect affinities for cortisol and testosterone. Therefore, R246 might be the key residue that determines the higher affinity of avian CBGs for progesterone, but not androgens, than for mammalian CBGs [83]. Given the compensatory function of bird CBG in transporting androgen, key mechanisms that govern androgen binding remain to be addressed. Functional studies of distinct residues of Zebra Finch CBG, such as N385 and other residues in the steroid-binding pocket, can be performed via mutagenesis to answer whether they determine androgen-binding properties. 


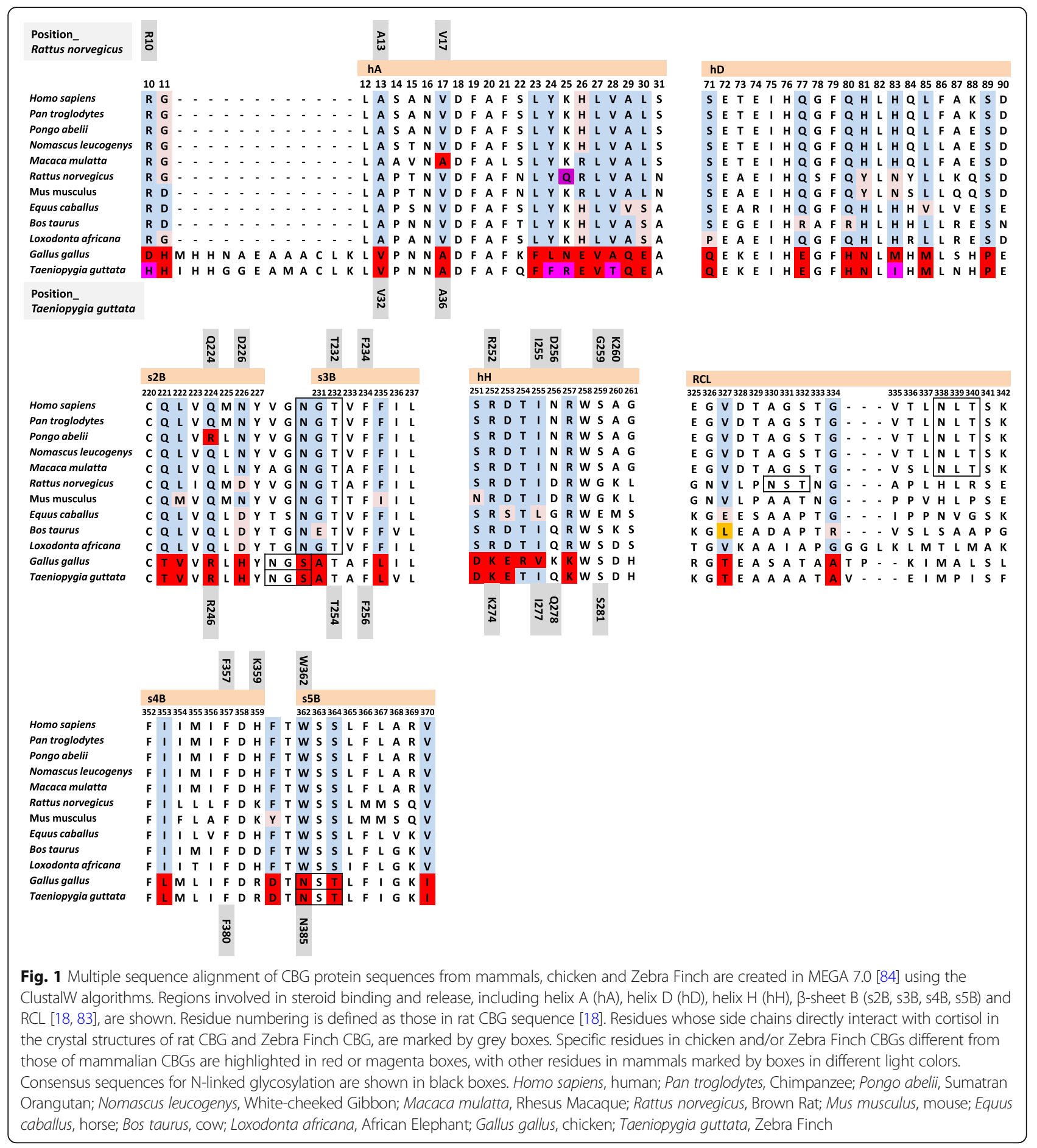

\section{Conclusions and perspectives}

As reviewed above, CBG functions beyond a mere plasma carrier protein and regulates biologically active fractions of circulating steroid hormones, and is therefore considered as a primary gatekeeper of steroid actions [9]. Since in vitro experimental and in vivo evidence have proved a single amino acid substitution in key domains of both mammalian and avian CBGs has profound effects on steroid binding properties, manipulation of CBG function via in-depth molecular, cellular and genetic studies in birds would provide more biological and ecological perspectives on how the unique structure of avian CBG determines its specialized androgen binding function, and how GCs and sex hormones are regulated during development, breeding, physiological behavior and adaptation in birds. 
A

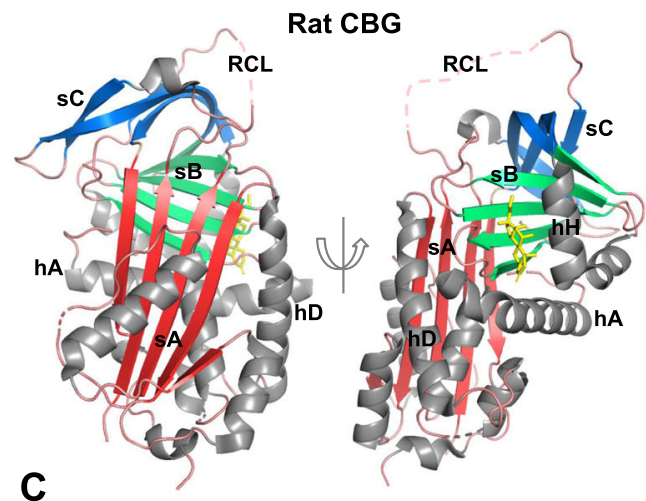

Zebra Finch CBG

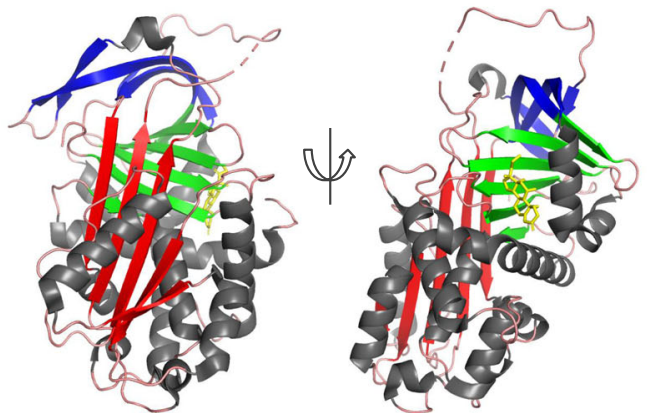

B

\section{Rat CBG_binding pocket}

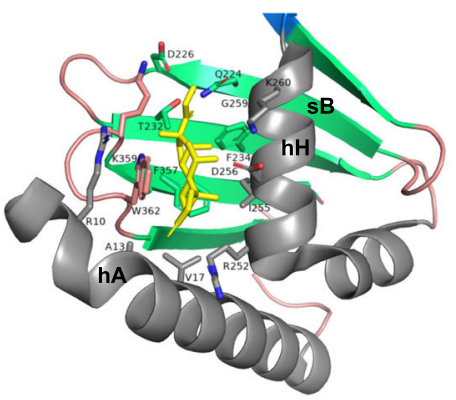

D
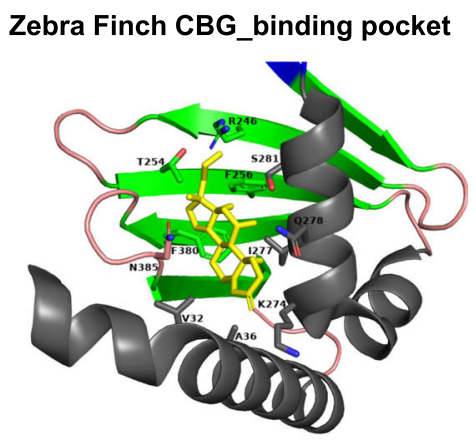

Fig. 2 Crystal structures and binding pockets of rat CBG (PDB code: 2v95) [18] and Zebra Finch CBG (PDB code: 5hgc) [83]. A, the native rat CBGcortisol structure. B, the cortisol-binding pocket of rat CBG. C, the native Zebra Finch CBG-cortisol structure. D, the cortisol-binding pocket of Zebra Finch CBG. The $\beta$-sheets A, B, and C are in red, green, and blue, respectively. Helixes are in grey. Cortisol is shown as stick models and coloured in yellow. The cartoons are prepared using PYMOL (http://pymol.sourceforge.net). In rat CBG, residues that directly interact with cortisol are R10, A13, V17 (in hA); Q224, D226 (in s2B); T232, F234 (in s3B); R252, I255, D256, G259, K260 (in hH); F357, K359 (in s4B); W362 (in s5B). In Zebra Finch CBG, cortisol-interacting residues include V32, A36 (in hA); R246 (in s2B); T254, F256 (in s3B); K274, 1277, Q278, S281 (in hH); F380 (in s4B); N385 (in s5B)

Evolutionary analysis of the SERPIN superfamily, to which CBG belongs, has revealed the linkage between signatures of positive Darwinian selection and the molecular basis of adaptive evolution. Evidence of strong positive selection has been detected in SERPINB4 and B3, as important drivers of adaptive evolution of mammals [88, 89]. Specially, the RCL region, the critical determinant of target proteinase recognition, is hypervariable and attributed to accelerated rates of evolution that drives the functional specificities and diversification [89-92]. In this regard, integrated phylogenetic, evolutionary and topographic analysis of CBGs of multiple organisms over broad taxonomic groups, such as those of mammals and birds, will provide the bedrock for understanding evolutionary conservation and species-specific adaptations in the process of endocrine responses to both extreme environmental perturbations and stressors associated with human activities in the age of Anthropocene.

\section{Abbreviations}

ACTH: Adrenocorticotropic hormone; CBG: Corticosteroid-binding globulin; CORT: Corticosterone; CRH: Corticotropin-releasing hormone;
DHT: Dihydrotestosterone; GCs: Glucocorticoids; HPA: Hypothalamuspituitary-adrenal; RCL: Reactive center loop; SERPINA: Serine proteinase inhibitor A; SHBG: Sex hormone-binding globulin; SNPs: Single nucleotide polymorphisms

\section{Acknowledgements}

We are grateful to Prof. Geoffrey L. Hammond at The Univeristy of British Columbia for his valuable comments and great help with editorial review.

\section{Authors' contributions}

H.Y.L., G.S., F.L., D.L. and Y.Q. are major contributors in writing the manuscript. Y.Q., D.L. and F.L. conceived and designed the article. All authors read and approved the final manuscript.

\section{Funding}

This work was supported by grants from the National Natural Science Foundation of China (NSFC) (32020103005, 81871170, 31971413, 32070434) and Beijing Natural Science Foundation (7192122).

Availability of data and materials Not applicable.

\section{Declarations}

Ethics approval and consent to participate Not applicable. 


\section{Consent for publication}

Not applicable.

\section{Competing interests}

The authors declare that they have no competing interests.

\section{Received: 7 December 2020 Accepted: 19 April 2021}

Published online: 29 April 2021

\section{References}

1. Sheriff MJ, Dantzer B, Delehanty B, Palme R, Boonstra R. Measuring stress in wildlife: techniques for quantifying glucocorticoids. Oecologia. 2011;166(4): 869-87. https://doi.org/10.1007/s00442-011-1943-y.

2. Herman JP, McKlveen JM, Ghosal S, Kopp B, Wulsin A, Makinson R, et al. Regulation of the hypothalamic-pituitary-adrenocortical stress response. Compr Physiol. 2016;6(2):603-21. https://doi.org/10.1002/cphy.c150015.

3. Toufexis D, Rivarola MA, Lara H, Viau V. Stress and the reproductive axis. J Neuroendocrinol. 2014;26(9):573-86. https://doi.org/10.1111/jne.12179.

4. Whirledge S, Cidlowski JA. A role for glucocorticoids in stress-impaired reproduction: beyond the hypothalamus and pituitary. Endocrinology. 2013 154(12):4450-68. https://doi.org/10.1210/en.2013-1652.

5. Oyola MG, Handa RJ. Hypothalamic-pituitary-adrenal and hypothalamicpituitary-gonadal axes: sex differences in regulation of stress responsivity. Stress. 2017;20(5):476-94. https://doi.org/10.1080/10253890.2017.1369523.

6. Mendel CM. The free hormone hypothesis: a physiologically based mathematical model. Endocr Rev. 1989:10(3):232-74. https://doi.org/10.121 0/edrv-10-3-232.

7. Mendel CM. The free hormone hypothesis. Distinction from the free hormone transport hypothesis. J Androl. 1992;13(2):107-16.

8. Hammond GL. Potential functions of plasma steroid-binding proteins. Trends Endrocrinol Metab. 1995;6(9-10):298-304. https://doi.org/10.1016/1 043-2760(95)00162-X.

9. Hammond GL. Plasma steroid-binding proteins: primary gatekeepers of steroid hormone action. J Endocrinol. 2016;230(1):R13-25. https://doi.org/1 0.1530/JOE-16-0070

10. Westphal U. Steroid-protein interactions II. Monogr Endocrinol. 1986;27:1603. https://doi.org/10.1007/978-3-642-82486-9 1.

11. Hammond GL, Smith CL, Paterson NA, Sibbald WJ. A role for corticosteroidbinding globulin in delivery of cortisol to activated neutrophils. J Clin Endocrinol Metab. 1990;71(1):34-9. https://doi.org/10.1210/jcem-71-1-34

12. Pemberton PA, Stein PE, Pepys MB, Potter JM, Carrell RW. Hormone binding globulins undergo serpin conformational change in inflammation. Nature. 1988;336(6196):257-8. https://doi.org/10.1038/336257a0.

13. Wingfield JC, Matt KS, Farner DS. Physiologic properties of steroid hormonebinding proteins in avian blood. Gen Comp Endocrinol. 1984;53(2):281-92. https://doi.org/10.1016/0016-6480(84)90254-5.

14. Lin HY, Muller YA, Hammond GL. Molecular and structural basis of steroid hormone binding and release from corticosteroid-binding globulin. Mol Cell Endocrinol. 2010;316(1):3-12. https://doi.org/10.1016/j.mce.2009.06.015.

15. Scrocchi LA, Orava M, Smith CL, Han VK, Hammond GL. Spatial and temporal distribution of corticosteroid-binding globulin and its messenge ribonucleic acid in embryonic and fetal mice. Endocrinology. 1993;132(2): 903-9. https://doi.org/10.1210/endo.132.2.7916682

16. Qi X, Loiseau F, Chan WL, Yan Y, Wei Z, Milroy LG, et al. Allosteric modulation of hormone release from thyroxine and corticosteroid-binding globulins. J Biol Chem. 2011;286(18):16163-73. https://doi.org/10.1074/jbc. M110.171082.

17. Meyer EJ, Nenke MA, Lewis JG, Torpy DJ. Corticosteroid-binding globulin: acute and chronic inflammation. Expert Rev Endocrinol Metab. 2017;12(4): 241-51. https://doi.org/10.1080/17446651.2017.1332991.

18. Klieber MA, Underhill C, Hammond GL, Muller YA. Corticosteroid-binding globulin, a structural basis for steroid transport and proteinase-triggered release. J Biol Chem. 2007;282(40):29594-603. https://doi.org/10.1074/jbc. M705014200.

19. Henley D, Lightman S, Carrell R. Cortisol and CBG - getting cortisol to the right place at the right time. Pharmacol Ther. 2016;166:128-35. https://doi. org/10.1016/j.pharmthera.2016.06.020

20. Lin HY, Underhill C, Gardill BR, Muller YA, Hammond GL. Residues in the human corticosteroid-binding globulin reactive center loop that influence steroid binding before and after elastase cleavage. J Biol Chem. 2009;284(2): 884-96. https://doi.org/10.1074/jbc.M807376200.
21. Simard M, Underhill C, Hammond GL. Functional implications of corticosteroid-binding globulin N-glycosylation. J Mol Endocrinol. 2018:60(2): 71-84. https://doi.org/10.1530/JME-17-0234.

22. Petersen $\mathrm{HH}$, Andreassen TK, Breiderhoff T, Brasen JH, Schulz H, Gross V, et al. Hyporesponsiveness to glucocorticoids in mice genetically deficient for the corticosteroid binding globulin. Mol Cell Biol. 2006;26(19):7236-45. https://doi.org/10.1128/MCB.00400-06

23. Willnow TE, Nykjaer A. Cellular uptake of steroid carrier proteins-mechanisms and implications. Mol Cell Endocrinol. 2010;316(1):93-102. https://doi.org/10.1016/j.mce.2009.07.021.

24. Richard EM, Helbling JC, Tridon C, Desmedt A, Minni AM, Cador M, et al. Plasma transcortin influences endocrine and behavioral stress responses in mice. Endocrinology. 2010;151(2):649-59. https://doi.org/10.1210/en.2009-0862

25. Moisan MP. CBG: a cortisol reservoir rather than a transporter. Nat Rev Endocrinol. 2013:9(2):78. https://doi.org/10.1038/nrendo.2012.134-c1.

26. Minni AM, Dorey R, Piérard C, Dominguez G, Helbling J-C, Foury A, et al. Critical role of plasma corticosteroid-binding-globulin during stress to promote glucocorticoid delivery to the brain: impact on memory retrieval. Endocrinology. 2012;153(10):4766-74. https://doi.org/10.1210/en.2012-1485.

27. Moisan MP, Minni AM, Dominguez G, Helbling JC, Foury A, Henkous N, et al. Role of corticosteroid binding globulin in the fast actions of glucocorticoids on the brain. Steroids. 2014;81:109-15. https://doi.org/10.1016/j.steroids.2 013.10.013.

28. Sivukhina EV, Jirikowski GF. Adrenal steroids in the brain: role of the intrinsic expression of corticosteroid-binding globulin (CBG) in the stress response. Steroids. 2014;81:70-3. https://doi.org/10.1016/j.steroids.2013.11.001.

29. Emptoz-Bonneton A, Cousin P, Seguchi K, Avvakumov GV, Bully C, Hammond GL, et al. Novel human corticosteroid-binding globulin variant with low cortisol-binding affinity. J Clin Endocrinol Metab. 2000;85(1):361-7. https://doi.org/10.1210/jcem.85.1.6315.

30. Torpy DJ, Bachmann AW, Grice JE, Fitzgerald SP, Phillips PJ, Whitworth JA, et al Familial corticosteroid-binding globulin deficiency due to a novel null mutation: association with fatigue and relative hypotension. J Clin Endocrinol Metab. 2001:86(8):3692-700. https://doi.org/10.1210/jcem.86.8.7724.

31. Van Baelen H, Brepoels R, De Moor P. Transcortin Leuven: a variant of human corticosteroid-binding globulin with decreased cortisol-binding affinity. J Biol Chem. 1982;257(7):3397-400. https://doi.org/10.1016/S0021-92 58(18)34790-2.

32. Van Baelen H, Power SG, Hammond GL. Decreased cortisol-binding affinity of transcortin Leuven is associated with an amino acid substitution at residue-93. Steroids. 1993;58(6):275-7. https://doi.org/10.1016/0039-128X(93 )90072-U.

33. Robinson PA, Hammond GL. Identification and characterization of a human corticosteroid binding globulin variant with a reduced affinity for cortisol. J Endocrinol. 1985;104(2):269-77. https://doi.org/10.1677/joe.0.1040269.

34. Smith CL, Power SG, Hammond GL. A Leu----his substitution at residue 93 in human corticosteroid binding globulin results in reduced affinity for cortisol. J Steroid Biochem Mol Biol. 1992;42(7):671-6. https://doi.org/10.101 6/0960-0760(92)90107-T.

35. Hill LA, Vassiliadi DA, Simard M, Pavlaki A, Perogamvros I, Hadjidakis D, et al. Two different corticosteroid-binding globulin variants that lack cortisolbinding activity in a greek woman. J Clin Endocrinol Metab. 2012;97(11): 4260-7. https://doi.org/10.1210/jc.2012-2467.

36. Cizza G, Bernardi L, Smirne N, Maletta R, Tomaino C, Costanzo A, et al. Clinical manifestations of highly prevalent corticosteroid-binding globulin mutations in a village in southern Italy. J Clin Endocrinol Metab. 2011;96(10): E1684-93. https://doi.org/10.1210/jc.2011-1321.

37. Brunner E, Baima J, Vieira TC, Vieira JG, Abucham J. Hereditary corticosteroid-binding globulin deficiency due to a missense mutation (Asp367Asn, CBG Lyon) in a Brazilian kindred. Clin Endocrinol. 2003;58(6): 756-62. https://doi.org/10.1046/j.1365-2265.2003.01783.x.

38. Lin HY, Underhill C, Lei JH, Helander-Claesson A, Lee HY, Gardill BR, et al. High frequency of SERPINA6 polymorphisms that reduce plasma corticosteroid-binding globulin activity in Chinese subjects. J Clin Endocrinol Metab. 2012;97(4):E678-86. https://doi.org/10.1210/jc.2011-3141.

39. Perogamvros I, Underhill C, Henley DE, Hadfield KD, Newman WG, Ray DW, et al. Novel corticosteroid-binding globulin variant that lacks steroid binding activity. J Clin Endocrinol Metab. 2010:95(10):E142-50. https://doi.org/10.121 0/jc.2010-0746. 
40. Torpy DJ, Lundgren BA, Ho JT, Lewis JG, Scott HS, Mericq V. CBG Santiago: a novel CBG mutation. J Clin Endocrinol Metab. 2012;97(1):E151-5. https://doi. org/10.1210/jc.2011-2022.

41. Lei JH, Yang $X$, Peng S, Li Y, Underhill C, Zhu C, et al. Impact of corticosteroid-binding globulin deficiency on pregnancy and neonatal sex. J Clin Endocrinol Metab. 2015;100(5):1819-27. https://doi.org/10.1210/jc.2 014-4254.

42. Utge S, Raikkonen K, Kajantie E, Lipsanen J, Andersson S, Strandberg T, et al. Polygenic risk score of SERPINA6/SERPINA1 associates with diurnal and stress-induced HPA axis activity in children. Psychoneuroendocrinology. 2018:93:1-7. https://doi.org/10.1016/j.psyneuen.2018.04.009.

43. van Gent D, Sharp P, Morgan K, Kalsheker N. Serpins: structure, function and molecular evolution. Int J Biochem Cell Biol. 2003;35(11):1536-47. https:// doi.org/10.1016/S1357-2725(03)00134-1.

44. Deviche P, Breuner C, Orchinik M. Testosterone, corticosterone, and photoperiod interact to regulate plasma levels of binding globulin and free steroid hormone in dark-eyed juncos, Junco hyemalis. Gen Comp Endocrinol. 2001;122(1):67-77. https://doi.org/10.1006/gcen.2001.7613.

45. Wingfield JC, Vleck CM, Moore MC. Seasonal changes of the adrenocortical response to stress in birds of the Sonoran Desert. J Exp Zool. 1992;264(4): 419-28. https://doi.org/10.1002/jez.1402640407.

46. Li D, Wang G, Wingfield JC, Zhang Z, Ding C, Lei F. Seasonal changes in adrenocortical responses to acute stress in Eurasian tree sparrow (Passer montanus) on the Tibetan plateau: comparison with house sparrow ( $P$. domesticus) in North America and with the migratory P. domesticus in Qinghai Province. Gen Comp Endocrinol. 2008;158(1):47-53. https://doi. org/10.1016/j.ygcen.2008.06.002.

47. De Rosa MJ, Veuthey T, Florman J, Grant J, Blanco MG, Andersen N, et al. The flight response impairs cytoprotective mechanisms by activating the insulin pathway. Nature. 2019;573(7772):135-8. https://doi.org/10.1038/s41 586-019-1524-5.

48. Wingfield JC, Patrick Kelley J, Angelier F, Chastel O, Lei F, Lynn SE, et al. Organism-environment interactions in a changing world: a mechanistic approach. J Ornithol. 2011;152(S1):279-88. https://doi.org/10.1007/s10336011-0668-3.

49. Mattbew IR, Ignacio TM, Kiran KS, Lei F, John CW. How similar are high latitude and high altitude habitats? A review and a preliminary study of the adrenocortical response to stress in birds of the Qinghai-Tibetan plateau. Acta Zool Sin. 2003:49:1-19.

50. Li D, Wu J, Zhang X, Ma X, Wingfield JC, Lei F, et al. Comparison of adrenocortical responses to acute stress in lowland and highland Eurasian tree sparrows (Passer montanus): similar patterns during the breeding, but different during the prebasic molt. J Exp Zool A Ecol Genet Physiol. 2011; 315:512-9.

51. Wingfield JC, Hunt KE. Arctic spring: hormone-behavior interactions in a severe environment. Comp Biochem Physiol B Biochem Mol Biol. 2002; 132(1):275-86. https://doi.org/10.1016/S1096-4959(01)00540-1.

52. Astheimer LB, Buttemer WA, Wingfield JC. Seasonal and acute changes in adrenocortical responsiveness in an arctic-breeding bird. Horm Behav. 1995; 29(4):442-57. https://doi.org/10.1006/hbeh.1995.1276.

53. Moller AP. Successful city dwellers: a comparative study of the ecological characteristics of urban birds in the Western Palearctic. Oecologia. 2009; 159(4):849-58. https://doi.org/10.1007/s00442-008-1259-8.

54. Beaugeard E, Brischoux F, Henry PY, Parenteau C, Trouve C, Angelier F. Does urbanization cause stress in wild birds during development? Insights from feather corticosterone levels in juvenile house sparrows (Passer domesticus). Ecol Evol. 2019;9(1):640-52. https://doi.org/10.1002/ece3.4788.

55. Partecke J, Schwabl I, Gwinner E. Stress and the city: urbanization and its effects on the stress physiology in European blackbirds. Ecology. 2006;87(8): 1945-52. https://doi.org/10.1890/0012-9658(2006)87[1945:SATCUA]2.0.CO;2.

56. Romero LM, Cyr NE, Romero RC. Corticosterone responses change seasonally in free-living house sparrows (Passer domesticus). Gen Comp Endocrinol. 2006;149(1):58-65. https://doi.org/10.1016/j.ygcen.2006.05.004.

57. Grunst $M$, Rotenberry J, Grunst A. Variation in adrenocortical stress physiology and condition metrics within a heterogeneous urban environment in the song sparrow Melospiza melodia. J Avian Biol. 2014 45(6):574-83. https://doi.org/10.1111/jav.00459.

58. Bókony $\mathrm{V}$, Seress $\mathrm{G}$, Nagy S, Lendvai ÁZ, Liker A. Multiple indices of body condition reveal no negative effect of urbanization in adult house sparrows. Landscape Urban Plan. 2012;104(1):75-84. https://doi.org/10.1016/j.la ndurbplan.2011.10.006
59. Schoech SJ, Romero LM, Moore IT, Bonier F. Constraints, concerns and considerations about the necessity of estimating free glucocorticoid concentrations for field endocrine studies. Funct Ecol. 2013;27(5):1100-6. https://doi.org/10.1111/1365-2435.12142.

60. Delehanty B, Bossart GD, Champagne C, Crocker DE, Elliott KH, Fair PA, et al. Measurement of free glucocorticoids: quantifying corticosteroid binding capacity and its variation within and among mammal and bird species. Conservation Physiology. 2020;8:coaa057.

61. Breuner CW, Orchinik M. Plasma binding proteins as mediators of corticosteroid action in vertebrates. J Endocrinol. 2002;175(1):99-112. https://doi.org/10.1677/joe.0.1750099.

62. Malisch $J \mathrm{~L}$, Breuner CW. Steroid-binding proteins and free steroids in birds Mol Cell Endocrinol. 2010;316(1):42-52. https://doi.org/10.1016/j.mce.2009. 09.019 .

63. Breuner CW, Lynn SE, Julian GE, Cornelius JM, Heidinger BJ, Love OP, et al. Plasma-binding globulins and acute stress response. Horm Metab Res. 2006; 38(4):260-8. https://doi.org/10.1055/s-2006-925347.

64. Shultz MT, Kitaysky AS. Spatial and temporal dynamics of corticosterone and corticosterone binding globulin are driven by environmental heterogeneity. Gen Comp Endocrinol. 2008;155(3):717-28. https://doi.org/10.1016/j.ygcen.2 007.11.002.

65. Fokidis HB, Orchinik M, Deviche P. Corticosterone and corticosteroid binding globulin in birds: relation to urbanization in a desert city. Gen Comp Endocrinol. 2009;160(3):259-70. https://doi.org/10.1016/j.ygcen.2 008.12 .005 .

66. Li D, Zhang X, Li Y, Hao C, Zhang J, Wu Y. Stress responses of testosterone and corticosterone-binding globulin in a multi-brooded species, Eurasian tree sparrows (Passer montanus): does CBG function as a mediator? Horm Behav. 2012;61(4):582-9. https://doi.org/10.1016/j.yhbeh.2012.02.007.

67. Lynn SE, Breuner CW, Wingfield JC. Short-term fasting affects locomotor activity, corticosterone, and corticosterone binding globulin in a migratory songbird. Horm Behav. 2003:43(1):150-7. https://doi.org/10.1016/S0018506X(02)00023-5.

68. Breuner CW, Delehanty B, Boonstra R. Evaluating stress in natural populations of vertebrates: total CORT is not good enough. Funct Ecol. 2013;27(1):24-36. https://doi.org/10.1111/1365-2435.12016.

69. Breuner CW, Beyl HE, Malisch JL. Corticosteroid-binding globulins: lessons from biomedical research. Mol Cell Endocrinol. 2020;514:110857. https://doi. org/10.1016/j.mce.2020.110857.

70. Silverin B. Corticosterone-binding proteins and behavioral effects of high plasma levels of corticosterone during the breeding period in the pied flycatcher. Gen Comp Endocrinol. 1986;64(1):67-74. https://doi.org/10.1016/ 0016-6480(86)90029-8

71. Wingfield JC. Organization of vertebrate annual cycles: implications for control mechanisms. Philos Trans R Soc Lond Ser B Biol Sci. 2008:363(1490): 425-41. https://doi.org/10.1098/rstb.2007.2149.

72. Dawson A, King VM, Bentley GE, Ball GF. Photoperiodic control of seasonality in birds. J Biol Rhythm. 2001;16(4):365-80. https://doi.org/10.11 77/074873001129002079.

73. Wingfield JC, Sapolsky RM. Reproduction and resistance to stress: when and how. J Neuroendocrinol. 2003;15(8):711-24. https://doi.org/10.1046/j.1365-2 826.2003.01033.x.

74. Romero LM. Seasonal changes in hypothalamic-pituitary-adrenal axis sensitivity in free-living house sparrows (Passer domesticus). Gen Comp Endocrinol. 2006;149(1):66-71. https://doi.org/10.1016/j.ygcen.2006.05.011.

75. Li M, Sun Y, Wu J, Zhang $X$, Li J, Yao Y, et al. Variation in corticosterone response and corticosteroid binding-globulin during different breeding substages in Eurasian tree sparrow (Passer montanus). J Exp Zool A Ecol Genet Physiol. 2016;325(1):75-83. https://doi.org/10.1002/jez.1998.

76. Williams CT, Kitaysky AS, Kettle AB, Buck CL. Corticosterone levels of tufted puffins vary with breeding stage, body condition index, and reproductive performance. Gen Comp Endocrinol. 2008;158(1):29-35. https://doi.org/10.1 016/j.ygcen.2008.04.018.

77. Romero LM, Reed JM, Wingfield JC. Effects of weather on corticosterone responses in wild free-living passerine birds. Gen Comp Endocrinol. 2000; 118(1):113-22. https://doi.org/10.1006/gcen.1999.7446.

78. Li D. A comparison of the adrenocortical responses to acute stress in cardueline finches from the Tibetan plateau, Arctic Alaska and lowland Western North America. J Ornithol. 2012;153(3):761-70. https://doi.org/10.1 007/s10336-011-0792-0. 
79. Breuner CW, Orchinik M, Hahn TP, Meddle SL, Moore IT, Owen-Ashley NT, et al. Differential mechanisms for regulation of the stress response across latitudinal gradients. Am J Physiol Regul Integr Comp Physiol. 2003;285(3): R594-600. https://doi.org/10.1152/ajpregu.00748.2002.

80. Wingfield JC, O'Reilly KM, Astheimer LB. Modulation of the adrenocortical responses to acute stress in arctic birds: a possible ecological basis. Am Zool. 1995;35(3):285-94. https://doi.org/10.1093/icb/35.3.285.

81. O'Reilly K, Wingfield J. Ecological factors underlying the adrenocortical response to capture stress in arctic-breeding shorebirds. Gen Comp Endocrinol. 2001;124(1):1-11. https://doi.org/10.1006/gcen.2001.7676.

82. Li D, Davis JE, Wang G, Nabi G, Bishop VR, Sun Y, et al. Coping with extremes: remarkably blunt adrenocortical responses to acute stress in two sympatric snow finches on the Qinghai-Tibet plateau during winter relative to other seasons. Gen Comp Endocrinol. 2020;291:113434. https://doi.org/1 0.1016/j.ygcen.2020.113434

83. Vashchenko G, Das S, Moon KM, Rogalski JC, Taves MD, Soma KK, et al. Identification of avian corticosteroid-binding globulin (SerpinA6) reveals the molecular basis of evolutionary adaptations in SerpinA6 structure and function as a steroid-binding protein. J Biol Chem. 2016;291(21):11300-12. https://doi.org/10.1074/jbc.M116.714378.

84. Kumar S, Stecher G, Tamura K. MEGA7: molecular evolutionary genetics analysis version 7.0 for bigger datasets. Mol Biol Evol. 2016;33(7):1870-4. https://doi.org/10.1093/molbev/msw054.

85. Zhou A, Wei Z, Stanley PL, Read RJ, Stein PE, Carrell RW. The S-to-R transition of corticosteroid-binding globulin and the mechanism of hormone release. J Mol Biol. 2008;380(1):244-51. https://doi.org/10.1016/j. jmb.2008.05.012.

86. Gardill BR, Vogl MR, Lin HY, Hammond GL, Muller YA. Corticosteroid-binding globulin: structure-function implications from species differences. PLoS One. 2012;7(12):e52759. https://doi.org/10.1371/journal.pone.0052759.

87. Avvakumov GV, Warmels-Rodenhiser S, Hammond GL. Glycosylation of human corticosteroid-binding globulin at aspargine 238 is necessary for steroid binding. J Biol Chem. 1993;268(2):862-6. https://doi.org/10.1016/ S0021-9258(18)54013-8.

88. Gomes S, Marques Pl, Matthiesen R, Seixas S. Adaptive evolution and divergence of SERPINB3: a young duplicate in great apes. PLoS One. 2014; 9(8):e104935. https://doi.org/10.1371/journal.pone.0104935.

89. Slodkowicz G, Goldman N. Integrated structural and evolutionary analysis reveals common mechanisms underlying adaptive evolution in mammals. Proc Natl Acad Sci U S A. 2020;117(11):5977-86. https://doi.org/10.1073/pna S.1916786117.

90. Barbour KW, Goodwin RL, Guillonneau F, Wang Y, Baumann H, Berger FG. Functional diversification during evolution of the murine alpha (1)proteinase inhibitor family: role of the hypervariable reactive center loop. Mol Biol Evol. 2002;19(5):718-27. https://doi.org/10.1093/oxfordjournals. molbev.a004130.

91. Hill RE, Hastie ND. Accelerated evolution in the reactive Centre regions of serine protease inhibitors. Nature. 1987;326(6108):96-9. https://doi.org/10.1 038/326096a0

92. Goodwin RL, Baumann H, Berger FG. Patterns of divergence during evolution of alpha 1-proteinase inhibitors in mammals. Mol Biol Evol. 1996; 13(2):346-58. https://doi.org/10.1093/oxfordjournals.molbev.a025594.

\section{Publisher's Note}

Springer Nature remains neutral with regard to jurisdictional claims in published maps and institutional affiliations.

Ready to submit your research? Choose BMC and benefit from:
- fast, convenient online submission
- thorough peer review by experienced researchers in your field
- rapid publication on acceptance
- support for research data, including large and complex data types
- gold Open Access which fosters wider collaboration and increased citations
- maximum visibility for your research: over 100M website views per year
At BMC, research is always in progress.
Learn more biomedcentral.com/submissions

